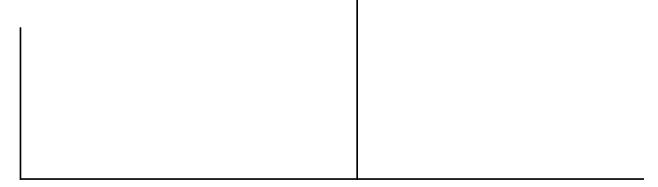

Rev. Latinoam. Psicop. Fund. VI, 2, 152-157

\title{
Esquirol e o surgimento da psiquiatria contemporânea*
}

\author{
Maria Vera Pompêo de Camargo Pacheco
}

Exatos 165 anos após sua publicação na França, o livro de Esquirol Das doenças mentais, ainda mantém uma força capaz de catalisar atenções. Os motivos desse interesse são bastante compreensíveis.

Reconhecido entre os grandes clássicos da psiquiatria francesa da primeira metade do século XIX, Étienne Esquirol posiciona-se como um dos marcos na fundação do pensamento psicopatológico contemporâneo. Desenvolveu um trabalho de continuação da obra de Pinel, como um de seus mais talentosos discípulos, e marcou sua atuação pela utilização sistemática da observação que lhe permitiu grande aprofundamento do trabalho clínico e uma delimitação precisa de quadros nosográficos da nascente psiquiatria contemporânea.

Se considerarmos as bases do pensamento científico sobre o qual a psiquiatria do século XIX apoiou-se, veremos que o trabalho de Pinel e seus seguidores representou uma verdadeira revolução de idéias.

* Apresentação realizada sob a orientação do Prof. Dr. Mário Eduardo Costa Pereira, do Laboratório de Psicopatologia Fundamental - Unicamp. 
Não havia até então um pensamento médico-científico sistematizado sobre a doença mental, e o louco não era assumido pela medicina como doente sob responsabilidade de seu campo de ação. Nos grandes asilos para alienados juntavam-se toda sorte de indivíduos pertencentes às minorias que representavam diversos problemas sociais, desde mendigos e delinqüentes a prostitutas e loucos de rua.

Apesar da loucura ter sido efetivamente considerada pertencente ao campo da medicina desde o final do século XVII, ainda não havia modelos ou definições claras, tampouco sistematizações nosográficas que pudessem caracterizar diferentes espécies clínicas do vasto gênero “loucura”. Eram muito grandes as variações entre os padrões que definiam os transtornos psíquicos: não se tinha uma visão abrangente e as descrições limitavam-se a algumas particularidades de sintomas.

A transformação metodológica introduzida por Pinel e Esquirol, fundamentada na observação clínica sistemática e na delimitação de categorias psicopatológicas estáveis, inscreve-se historicamente em um momento em que a medicina tinha a clara preocupação de diferenciar-se da filosofia, da psicologia e da religião, cujos objetos de conhecimento transcendem o corpo ou a matéria, indagando sobre temas espirituais, lógico-discursivos e/ou ético-estéticos. As ciências médicas buscavam, então, firmar seus princípios baseados em critérios objetivos e com nítida aproximação dos métodos das ciências naturais. O diagnóstico médico não podia, portanto, prender-se na observação do comportamento, para não sofrer a indesejável interferência de dados subjetivos. Firmava-se a concepção de "doença mental” como uma decorrência de distúrbios orgânicos provindos de disfunções de estruturas orgânicas, ou ainda de lesões anatômicas ou funcionais do encéfalo, e que se refletiam no comportamento sob a forma de sintomas.

Contudo, a preocupação de Pinel e, em seguida, de Esquirol era menos a de construir uma teoria biológica da loucura do que conhecer e bem delimitar suas apresentações clínicas.

Pinel introduziu a concepção da loucura como conseqüência das paixões exacerbadas, e o louco como vítima de uma desorganização das funções mentais superiores do sistema nervoso central, ou seja, das funções intelectuais, pressuposto que deu nova direção à psiquiatria do final do século XVIII e início do século XIX.

Este grande alienista francês impôs em seu trabalho uma preocupação com a classificação nosográfica e, em sua clínica, uma prática inovadora: a observação empírica sistemática e o tratamento moral. Ao considerar o indivíduo alienado como doente mental, vítima de disfunções psíquicas, Pinel deu a eles o direito de serem ouvidos e conferiu à medicina a necessidade de entendê-los e tratá-los 
humana e respeitosamente. Foi, portanto, um dos primeiros médicos psiquiatras a conceder o estatuto de dignidade aos loucos, diferenciando-os dos bandidos e dos criminosos comuns, e transformando com essa abordagem, o conceito de instituição para doentes mentais.

Quanto à etiologia, Pinel reconhece as causas hereditárias como responsáveis pela doença, mas ressalta a influência essencial de outros fatores não-hereditários, como os acontecimentos externos e as emoções violentas, determinando o quadro mórbido. Focalizou sua atenção sobre a mania ou delírio total, que considerou como a forma mais típica e mais comum de loucura.

Esquirol, em seguida, por sua visão ampla e seu comprometimento com o trabalho clínico, imprimiu mudanças expressivas na psiquiatria de sua época, prosseguindo e aprofundando o trabalho de Pinel. Mesmo conservando o pressuposto das causas físicas e morais atuando simultaneamente na determinação da doença mental, Esquirol representou um avanço expressivo no plano teórico ao propor nova sistematização nosográfica, a partir de uma análise fina e de uma diferenciação mais detalhada das síndromes psicopatológicas.

No campo mais específico do saber e da prática psiquiátrica, Esquirol também produziu uma mudança importante ao rever o conceito de melancolia depois de pesquisá-la e descrevê-la longamente.

Ordenou então sua classificação nosográfica, diferenciando quatro grupos principais de doenças mentais, por meio dos quais procurou separar as perturbações de fundo claramente orgânico das perturbações de natureza psíquica, consideradas disfunções mentais:

- Idiotia: que pode ser congênita ou adquirida, mas constitui uma categoria bastante diferenciada das que agrupam os problemas propriamente psíquicos.

- Demência: na forma aguda, passível de cura, e na forma crônica, praticamente incurável.

- Mania: que refere-se ao delírio total com exaltação. Seria uma alteração generalizada das funções mentais, como a inteligência, percepção, volição, atenção.

- Monomanias: que agrupa todas as perturbações mentais que trazem prejuízos psíquicos apenas parciais, conservando perfeitas outras funções intelectuais. O delírio é parcial e pode ter uma forma alegre ou uma forma triste.

Aqui encontra-se a contribuição mais original e também mais controvertida de Esquirol: a separação da melancolia, da antiga classificação de Pinel, em duas categorias diferentes - a mania e a lipemania, umas das formas de monomania. Esse termo foi escolhido por ele com o objetivo de resolver as ambigüidades e confusões que a palavra melancolia comportava.

A lipemania consistiria num delírio intelectual, de natureza depressiva, situado em primeiro plano e que acabaria por afetar toda a vida do paciente 
incapacitando-o para as mais simples atividades. Esta designação não permanece, todavia, muito tempo na nosografia psiquiátrica: o termo melancolia volta a ser utilizado numa categorização reformulada.

Estes foram passos que antecederam a descrição de Jean-Pierre Falret de uma "forma circular de doença mental" na qual ocorria um período de excitação seguido de outro longo período de tristeza, e a postulação do termo "loucura de dupla forma”, de Baillanger. Chegou-se, assim, no final do século XIX, com a evolução do conhecimento psicopatológico, a uma das discriminações nosológicas mais fundamentais da psiquiatria: a separação da demência precoce da psicose maníaco-depressiva, estabelecida por Kraepelin.

No que se refere à terapêutica, Esquirol deu continuidade à prática de um tipo de tratamento diferenciado: o tratamento moral iniciado por Pinel. Esta abordagem estruturou-se em decorrência dos pressupostos teóricos a respeito da loucura que, deixando de ser exclusivamente organicista, passou a considerar o aspecto psicológico como fundamental na determinação da doença. As experiências vividas pelo paciente adquirem assim um novo valor como dados a serem observados e considerados no conhecimento de suas funções mentais. A compreensão dessas funções mentais já não se dá pela noção de sistemas gerais de explicação causal e, dessa forma, se o adoecer é parte da experiência sensorial do sujeito, a loucura pode ser um estado reversível.

Esquirol situou-se nesses princípios para melhor sistematizar o conhecimento e a prática psiquiátrica de sua época. Endossou a idéia de que as paixões exacerbadas poderiam desencadear as grandes perturbações mentais e considerou também que os procedimentos terapêuticos capazes de apaziguá-las seriam um meio de reconduzir o doente a encontrar a coerência entre a realidade percebida pelos sentidos e as funções mentais, pelas suas idéias, raciocínios, julgamentos.

O tratamento moral tinha, portanto, um sentido educativo que envolvia aspectos ambientais e sociais. No entanto, a idéia de que através dos métodos psicológicos seria possível corrigir erros na lógica de pensamento e raciocínio daqueles que se afastavam da norma admitida como correta, implica uma questão ética que podia facilmente justificar condutas arbitrárias ou coercitivas.

E nesse sentido Esquirol teve uma postura de autoritarismo, segundo o olhar de hoje, ao pressupor que a conduta terapêutica, para se opor às idéias delirantes, não podia usar apenas a compreensão, a persuasão e os conselhos lógicos, mas deveria introduzir diversas formas de "choque" que perturbassem emocionalmente o paciente para fazê-lo adotar uma idéia oposta à de sua lógica delirante.

Nesse momento da história da psiquiatria, o louco ainda não era efetivamente ouvido em seu sofrimento. O delírio era considerado apenas como uma forma patológica de juízo distorcido e o tratamento moral consistiria em um es- 
forço de confrontação do sujeito com seu erro, de modo a reabilitá-lo ao convívio social.

A ação de Esquirol estendeu-se ainda a outro plano, onde sua sensibilidade para a clínica o levou a considerar o drama da vida cotidiana de um doente mental na instituição de alienados. Lutou pela nova lei de internação, que entrou em vigor em 1838, trazendo melhores condições aos pacientes psiquiátricos e iniciando a época dos grandes asilos, onde a loucura passou a ser definitivamente associada às práticas sistemáticas da medicina. Um grande desafio que durante longos anos seguintes motivaram seu esforço de prover a psiquiatria dos mesmos instrumentos científicos racionais e precisos de diagnóstico e terapêutica da medicina em geral.

Nesse período em que o corpo já fora desmistificado pelo desenvolvimento da anatomia, dispondo-se como objeto de conhecimento científico, o psiquismo permanecia cercado de mistérios e a doença mental, uma nebulosa plena de questões.

A história do pensamento sobre a loucura e seu tratamento encontra um ponto referencial em Esquirol. Ele defende a idéia de que a relação com o médico desempenha um papel importante na cura, e nessa mudança de concepção vai fundamentando a noção de que a liberdade do sujeito é vista como condição necessária ao aparecimento de sua verdade de louco, como descreve Foucault (1978). A psiquiatria não poderia, portanto, a seu ver, estar ligada à filosofia ou à religião, mas sim lançar-se em busca de um método próprio sem, no entanto, pautar a compreensão dos transtornos psíquicos apenas pelas causas orgânicas.

Encontramos então um esboço inicial dos métodos psicológicos de tratamento das doenças mentais. Abrir a possibilidade de ouvir o paciente significa tirá-lo da condição de objeto avariado, incompreensível e irrecuperável para devolver-lhe a condição de um sujeito que nos propõe o enigma do mundo interno.

A prática de Esquirol, no entanto, não se limitou a uma abordagem clínica pontual de sintomas, suas causas biopsíquicas e sua evolução terapêutica. Vivendo na época de grandes transformações sociais, no rastro da Revolução Francesa, de passado ainda recente, uma de suas mais interessantes contribuições foi a consideração dos transtornos sociais como desencadeantes de doenças mentais.

Foucault aponta o fato de que na época compreendia-se a loucura a partir de uma concepção moldada na consciência histórica das grandes transformações que sobrevieram à Revolução Francesa e mantiveram a situação de extrema conturbação, repressão e violência social, submetendo os homens a inseguranças e intensas paixões responsáveis por profundos desequilíbrios psíquicos (Foucault, 1978).

Foram a percepção e a sensibilidade a esses elementos que permitiram a Esquirol o desenvolvimento de um trabalho que ainda hoje nos lança questões. Seus textos sobre as monomanias reconheceram, por exemplo, a ocorrência de 
uma perturbação localizada, alterando apenas uma área do funcionamento psíquico do sujeito e levando-o à insanidade e à possibilidade de cometer atos anti-sociais, inclusive mesmo assassinatos. A monomania instintiva seria, dessa forma, a responsável pelas situações de graves delitos cometidos aparentemente sem motivo.

Seguiram-se daí longas discussões, envolvendo tanto a área médica quanto a jurídica, ao se levantar a questão da atribuição de responsabilidade ao criminoso. Como julgá-lo, se ele é vítima de uma "ação instintiva irresistível”, não tendo domínio sobre sua própria vontade ou razão?

Uma retomada histórica dos caminhos por onde passou a elaboração do saber psicopatológico atual, por meio de textos clássicos, como este de Esquirol - "Da lipemania ou melancolia" - permite-nos um contato com o quadro de sintomas, tal como as cuidadosas descrições da psiquiatria clássica nos apresentam, o que hoje nos é barrado pela farmacologia. É um mergulho profundo no mundo da loucura, onde havia poucas esperanças de um retorno sem conseqüências.

Este texto expressa claramente o pensamento de Esquirol e sua prática clínica.

E temos além disso, indiretamente revelado, o diálogo que a psiquiatria empreendeu não apenas no interior de sua especificidade no campo das ciências médicas, mas também com a psicanálise, a filosofia, a sociologia, a antropologia, buscando divergências e convergências de opiniões que ao longo desses anos têm retornado à cena do diálogo.

\section{Referências}

Bercherie, P. Histoire et structure du savoir psychiatrique - les fondements de la clinique I. Paris: Ed. Universitaires, 1991.

Foucault, M. História da loucura. São Paulo: Perspectiva, 1978.

Pessotti, I. A loucura e as épocas. Rio de Janeiro: Editora 34, 1994.

Postel, J. \& Quetel, C. Nouvelle histoire de la psychiatrie. Toulouse: Privat, 1983. Postel, J. La psychiatrie. Paris: Larousse, 1994. 